\title{
Types of maps used as a stimuli in cartographical empirical research
}

\section{Abstract}

Revisions of achievements of empirical studies in cartography focused on describing main research themes and diagnosing challenges to be approached. Intriguingly, there is no analysis of maps used as a stimuli in these experiments. In order to fill existing scarcity, this paper presents the analysis of the content of four journals affiliated by the International Cartographic Association. Four features (map medium, reactiveness, method of cartographic presentation, users familiarity with the depicted data) are described based on 103 papers presenting empirical studies. Types of maps were identified in scope of every feature. Most frequently used ones are displayed on the screen, non-interactive, depicting qualitative data and area unfamiliar for the participant of the study.

Keywords

Cartography $\cdot$ map $\cdot$ empirical research $\bullet$ map perception

(c) University of Warsaw - Faculty of Geography and Regional Studies
Katarzyna Słomska

Department of Geoinformatics, Cartography and Remote Sensing. Faculty of Geography and Regional Studies, University of Warsaw, Poland e-mail: slomska.k@gmail.com

Received: 18 December 2017

Accepted: 11 May 2018
Introduction

Empirical studies in cartography allow users' perceptions of maps and GIS to be explored. Consequently, cartographic and GIS products may be adapted to user needs. The first attempts were inspired by the book The look of maps (Robinson 1985), which was first published in 1952 and is recognised as the beginning of cognitive cartography. Robinson suggested turning attention to the map-user's needs, abilities and limitations. This resulted in the field of cognitive cartography emerging, and empirical studies became commonly used by cartographers.

The development of this research field has been described by e.g. Montello (2002; 2009) and Żyszkowska (2015). There have been two important shifts in researchers' approaches. In the very beginning, cartographers focused on particular elements of a map and tested them in isolation. For instance, Flannery (1956), who studied the use of circles in proportional symbols maps. The first revision was influenced by, among others, the work of Petchenik (1977), who highlighted that a map constitutes a unity in itself and suggested that a holistic approach would be more suitable. This initiated a switch from testing specific elements of a map to analysing the perception of a map as a whole.

According to Montello (2009) another turning point for empirical research conducted by cartographers was initiated by technological development in the late 1990s. Easier access to new technologies, software and devices caused the interest of cartographers to turn to the cognition of maps displayed on screens and, with time, interactive maps. What is more, new types of geovisualisations came about. The new century brought new opportunities for the development of the field. New methods are used, but also the scope of geovisualisations and types of maps is wider. Nonetheless, in its every shape, empirical research was and still is a significant part of cartography. That is why analysis of its achievements is crucial for further development. The literature lacks analyses of the progress of cognitive cartography in the 21 st century. What is more, it cannot be studied separately from the field of geovisualisation, as they influence each other.

\section{Related papers}

Over time, the field of cognitive cartography has been revised by several researchers. Gilmartin (1992) reviewed the content of three journals: Cartographica (currently known as "Cartographica: The International Journal for Geographic Information and Geovisualization"), The Cartographic Journal, and The American Cartographer (currently known as "Cartography and Geographic Information Science") published in the years 1964-1989. Useroriented studies, in which experimental studies were included, were the most popular research theme, comprising as much as $30 \%$ of all published papers in the 1970s (Gilmartin 1992).

Review papers attempt to identify research topics in cognitive studies in cartography by analysing the scope of research. Slocum et al. (2001) propose classification of research themes in geovisualisation in a cognitive context. The following topics are enumerated: geospatial virtual environments, dynamic representations, user interface design, individual and group differences, collaborative geovisualisation, and evaluating the effectiveness of geovisualisation methods. Vast descriptions of the evolution of the field with a division for particular topics, such as, e.g., education, ontology and the impact of empirical studies on cartographic practice have been described by Montello 
MISCELLANEA GEOGRAPHICA - REGIONAL STUDIES ON DEVELOPMENT

Vol. 22 - No. 3 • 2018 • pp. 157-171 • ISSN: 2084-6118 • DOI: 10.2478/mgrsd-2018-0014

Table 1. Number of analysed papers per journal (since 2000)

\begin{tabular}{|c|c|c|c|c|}
\hline Title of a journal & $\begin{array}{l}\text { Published } \\
\text { since }\end{array}$ & $\begin{array}{c}\text { Number of } \\
\text { published papers } \\
\text { since } 2000(\mathrm{nPp})\end{array}$ & $\begin{array}{c}\text { Number of } \\
\text { analysed papers } \\
\text { since } 2000 \text { (nAp) }\end{array}$ & $\frac{\mathrm{nAp}}{\mathrm{nPp}} \times 100 \%$ \\
\hline The Cartographic Journal & 1964 & 422 & 40 & $9.5 \%$ \\
\hline $\begin{array}{l}\text { Cartographica: The International Journal for } \\
\text { Geographic Information and Geovisualization }\end{array}$ & 1965 & 273 & 17 & $6.2 \%$ \\
\hline $\begin{array}{c}\text { Cartography and Geographic Information } \\
\text { Science }\end{array}$ & 1973 & 465 & 39 & $8.4 \%$ \\
\hline International Journal of Cartography & 2015 & 36 & 7 & $19.4 \%$ \\
\hline & & 1196 & 103 & $8.6 \%$ \\
\hline
\end{tabular}

Source: own elaboration

(2002) and Montello and Freundschuh (2005). Moreover, Montello (2009) focused on the achievements of empirical research in the context of GIS within the scope of navigation, geovisualisation, human factors in GIS, education and ontology. All these aforementioned papers suggested further research challenges to be addressed. However, the issues they focused on were different from one another; Montello (2002) recommended analysing the history of cognitive map-design research, whereas Slocum et al. (2001) endorsed the development of an interdisciplinary approach.

Roth (2013a) applied another approach to reviewing the achievements of experimental studies in cartography. The author juxtaposed 25 classifications of cartographic interactions published from 1987 to 2008 . On the basis of this overview, a taxonomy of cartographic interaction primitives based on objective, operator and operand was proposed. The analysis outlined the most common tasks used in research in the context of user goal, data and the interface. Moreover, definitions and prioritised interaction primitives were provided. This work is a systematisation of previous knowledge and it constitutes a framework for future studies and makes them easier to compare and validate.

The same aim was shared by White (2017), who created a consistent database of 200 cartographical user-studies in order to gauge them. He focused on participants who took part in experiments in the contexts of recruitment, verification and evaluation. This overview can be recognised as a base of good and bad practices, so that common mistakes would not be perpetuated in later studies.

Issues such as evolution of the field, main research themes, the importance of participant selection and dimensions of interaction were analysed and described. Notably, the maps that are used as stimuli in empirical cartographical research never underwent revision.

\section{Research outline}

The preparation of the empirical study in cognitive cartography is crucial to the quality of their results and conclusions drawn. Every aspect - such as the selection of stimuli, participants or methods - has to be conducted deliberately, as it will have an impact on the results.

Roth's paper (2013a) constitutes a canvas for standardising experimental studies. A similar approach may be applied towards other elements of an empirical study in cartography. Despite the study areas in cartography being different, such as geovisualisation, cognitive cartography, communication theory or modelling approach, all cartographers have one common interest - a map.

The main aim of this paper is to present types of maps used as stimuli in empirical studies in cartography in the context of the user and researcher perspective. Such revisions could possibly bring such opportunities as the taxonomy of interaction primitives proposed by Roth (2013a). In many papers it is not stated clearly whether elements of the study were interactive and if so, which, nor whether the participants had previous knowledge of the data or the area depicted on the map, etc. In some cases, there is also no graphic example of a map included. Organised description of the stimuli would provide an opportunity for repetition and, consequently, verification of results.

Therefore, the material to be analysed must be delimited. As stated before, it was decided to focus on papers published since 2000. The query covers journals affiliated to the ICA: The Cartographic Journal, Cartographica: The International Journal for Geographic Information and Geovisualization, and Cartography and Geographic Information Science, and the journal published by the ICA: the International Journal of Cartography. From the wide scope of geovisualisations used in empirical studies only maps were included; therefore, such works as user-studies of interfaces or tactile maps were excluded. The analysis of a great variety of differing forms would constitute a problem in terms of comparing them against maps, because of, e.g., their multidimensionality or application of virtual reality.

The review juxtaposed 103 research papers presenting an experiment where a map was used as the stimulus. They constituted $8.6 \%$ of papers published in the mentioned journals since 2000 (Table 1), so the stake is three times smaller than in the late 1970s (Gilmartin 1992). What is interesting is that the International Journal of Cartography, which has only been in publication since 2015, had the highest stake of papers concerning empirical studies.

In the analysed period the number of research papers concerning empirical studies in cartography has risen (Fig. 1). It is worth noticing that Cartographica: The International Journal for Geographic Information and Geovisualization was not published in 2002 and 2003, and the International Journal of Cartography was launched in 2015.

The attributes of maps used for the identification of map types were chosen on the basis of the author's description of stimuli. Four main features were chosen (Table 2, Fig. 2): map medium (paper, screen), reactiveness (interactive, noninteractive), method of cartographic presentation (quantitative, qualitative), users' familiarity with the presented area and data (familiar, unfamiliar, fictional). In most experiments more than one type of map was used, but the aim was rarely to compare them. Such experiments are presented in figure 2 as transitional areas, marked by vertical banding in the middle of the figure, in order to point out differences in overlapping proportions between features. The same solution was applied to the graphs, which show proportions of different types through the analysed period 


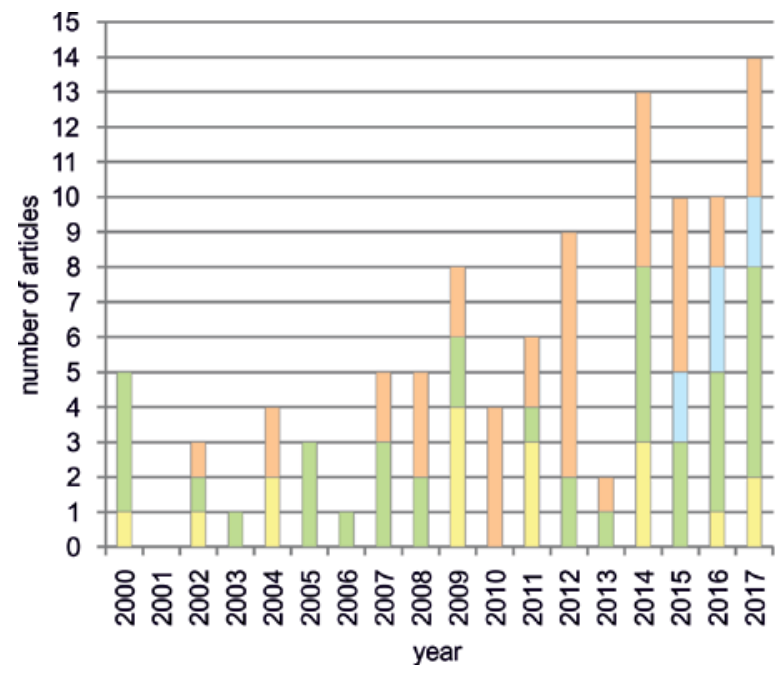

$\square$ The Cartographic Journal (41)

- International Journal of Cartography (7)

$\square$ Cartography and Geographic Information Science (38)

$\square$ Cartographica: The International Journal for Geographic Information and Geovisualization (17)

Figure 1. Number of analysed papers per year Source: own elaboration

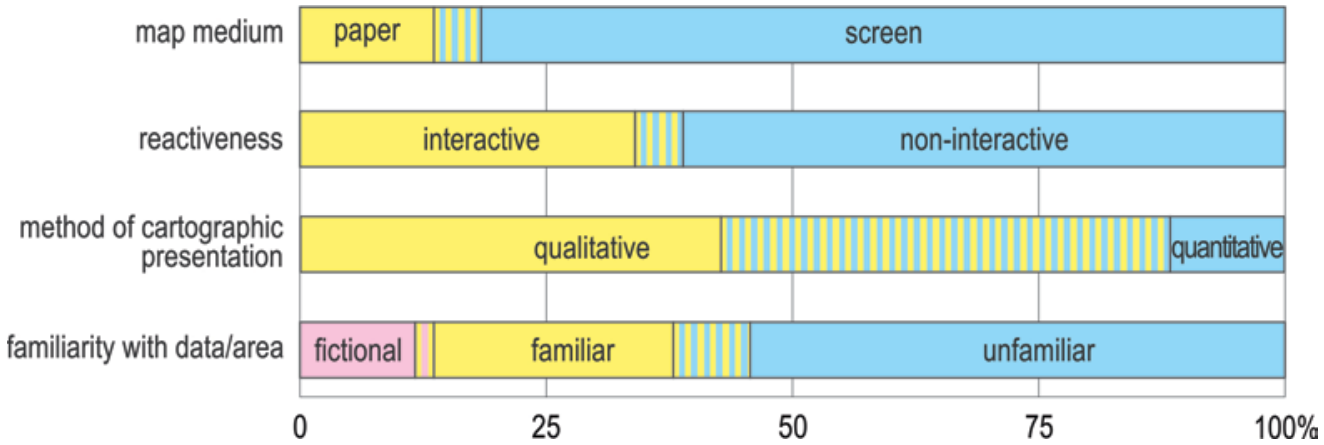

Figure 2. Percent of map types used in analysed papers

Source: own elaboration

(Fig. 3, Fig. 5, Fig. 6, Fig. 7). The green parts of bars in figures 3 , 5,6 and 7 and the vertical banding in figure 2 depict cases when both types were used in the same study.

Unfortunately, it is not possible to specify the number of maps used as stimuli in the analysed papers, as authors do not always provide this information.

\section{Results}

Map medium

The paper map may be considered the most traditional form. Although digital natives, who are proficient in technology, may associate the word "map" with a display on the screen of a laptop, smartphone or navigation device (Prensky 2001). There are more possibilities for presenting a map, but paper and screen are the most common media of transmission.

The stimuli of the first studies were only presented on paper. With the development of technology and research methods, display on a screen has become more common. Since 2000, about $86 \%$ of maps used in research have been displayed on a screen (Table 2, Fig. 2). They may be in different forms, from a raster of a scanned and calibrated paper map to a vector map outputted by a database (Ooms et al. 2012). It is worth noticing that the disproportion between use of paper and screen as a medium is large compared to differences among map types in other aspects. Screens were used as the medium for a map four times more often than paper (Table 2). This may be in response to user preferences. Users' turn from paper to digital maps is noticeable, especially when it comes to the navigational functions (Axon et al. 2012; Speake \& Axon 2013; Speake 2016). The disproportion may also be connected with the use of map applications prepared for the study and/or use of eye-tracking, which is often used as a supplementary method (Ooms et al. 2014; Opach et al. 2014). Applications facilitate control over the flow of the experiment, measurement of time needed for particular questions, and analysis of eye and mouse movements (e.g. open-source OGAMA, Vosskühler et al. 2008).

Traditional maps are disappearing from everyday life, and as a consequence are not often selected as stimuli in research. They were used in only $18 \%$ of analysed cases (Table 2.) Providing ecological validity (Carter et al. 2008) and obtaining comparable results were always a challenge for researchers. This obstacle may be easily overcome, as most study participants (who are mainly recruited from among students or faculty staff) use a computer or smartphone on a daily basis (Slocum et al. 2004). Problems may arise in the case of recruiting participants from an elderly population. Nonetheless, differences in level of proficiency in the use of computer and devices like smartphones must be taken into consideration (Andrienko et al. 2002; Opach \& Rød 2014). What is interesting is that researchers may nowadays also include the possibility of inequalities in proficiency using paper maps, as young people and/or novice users consider it to be more challenging (Speake 2016). It may be thought-provoking that 


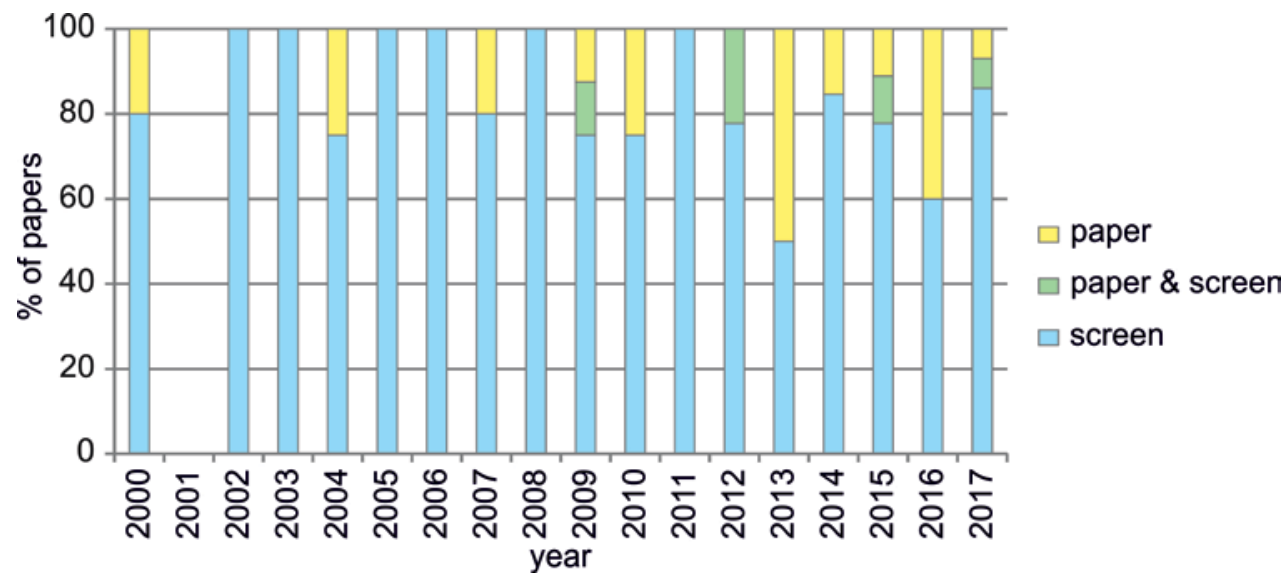

Figure 3. Percentage of paper and screen maps

Source: own elaboration

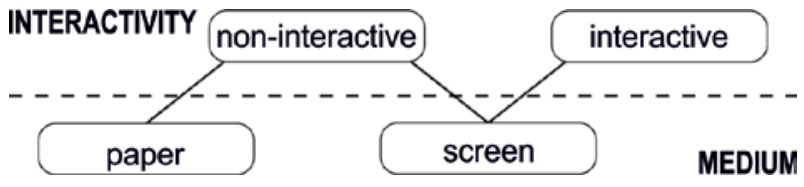

Figure 4. Relation between medium and level of reactiveness Source: own elaboration based on Kraak \& Brown 2001

the percentage of paper maps used in experiments has risen (Fig. 3).

Reactiveness

By level of reactiveness, maps can be divided into interactive and non-interactive (view only) (Kraak \& Brown 2001). The reactiveness of a map is strongly connected with its medium, as all paper maps are non-interactive (Fig. 4). Digital maps can be interactive or non-interactive. The relationship between the discussed map features is presented in the following diagram (Fig. 4), where the horizontal dotted line represents the distinction between them and uninterrupted lines show relations between.

However, this type of view-only map, which is not editable, can also be displayed on a screen. Non-interactive maps constituted $66.0 \%$ of stimuli displayed on the screen (Table 2, Fig. 2). On the other side, interactive maps are inseparably related to electronic devices. Examples may be identified among geoportals, map applications, or GIS software.

Oxford Dictionaries defines reactive as "showing a response to a stimulus", and interactive as "allowing a two-way flow of information between a computer and a computer-user; responding to a user's input" (Oxford Dictionaries 2017). What is more, the map is given as an example ("a fully interactive map of the area").

Responding to the map-readers' input is also stressed in another definition, which states that an "interactive map reciprocates spatial information between map and map-reader" (Cartwright et al. 2007, p 156). According to Roth (2013b, p 64) cartographic interaction is "a dialogue between a human and a map mediated through a computing device". In every definition, user and map are equal subjects.

Emphasis should be put on the word "map", as its content should be interactive, not only the environment (e.g. the interface). Furthermore, both discussed types of maps can be dynamic (Kraak \& Brown 2001). That is why, in this paper, dynamic display (animation) is not considered as a form of interaction, as was also the case in a study by Saint-Marc et al. (2017): neither are panning or zooming of a static display, unless it is a semantic zoom, which involves changes in the level of data generalisation (Tanaka \& Ichikawa 1988).

The differences in usability of non-interactive and interactive maps is one of a prevailing research questions in cartography (Roth et al. 2017). The comparison may state a challenge, because of the differences between them (e.g. medium, graphic variables). An even greater obstacle may be presented by the difficulty in comparing experiment results, as an interactive map may enable automatic measurements of length and area, filtration and selection of data. These functions substitute skills obtained during map usage. It is one of the causes of the shift in user preferences (Axon, Speake \& Crawford 2012).

The need for a comparison of non-interactive and interactive maps is crucial mainly due to the use of maps in education. According to Harvey and Kotting (2011), active learning with interactive display matches the needs of digital natives. Downsides may also be recognised, as software substitutes thinking because it processes information for users (Montello 2009). At this point, it is also worth tackling the issue of level of proficiency in using interactive maps among participants, as in the case of the map medium.

Non-interactive maps are more often used as a stimulus (66\% of analysed studies) (Table 2, Fig. 2). There may be several causes for this. First, they allow studies of holistic map perception to be conducted, as users cannot choose layers to be displayed, change symbolisation or colours. When it comes to interactive maps, cartographers have to pre-define the limitations of the modifications (Kraak \& Brown 2001; Kraak \& Ormeling 2015). Therefore, the purpose is to check the usability of one of the aspects, or the interface. However, the disproportion is not as big as in the case of the map medium. Interactive maps were used in $39 \%$ of studies (Table 2.) It is interesting that the proportion is stable over time, since it would be expected that the share of interactive stimuli should rise. In five papers, interactive and non-interactive displays are used to simultaneously show different information (Behrens et al. 2015) (Fig. 2).

\section{Method of cartographic presentation}

For the purpose of identification of map types, methods of cartographic presentation are considered in the context of data. In cartographic literature the distinction between qualitative, quantitative and ordinal data is used. "Qualitative" means records 


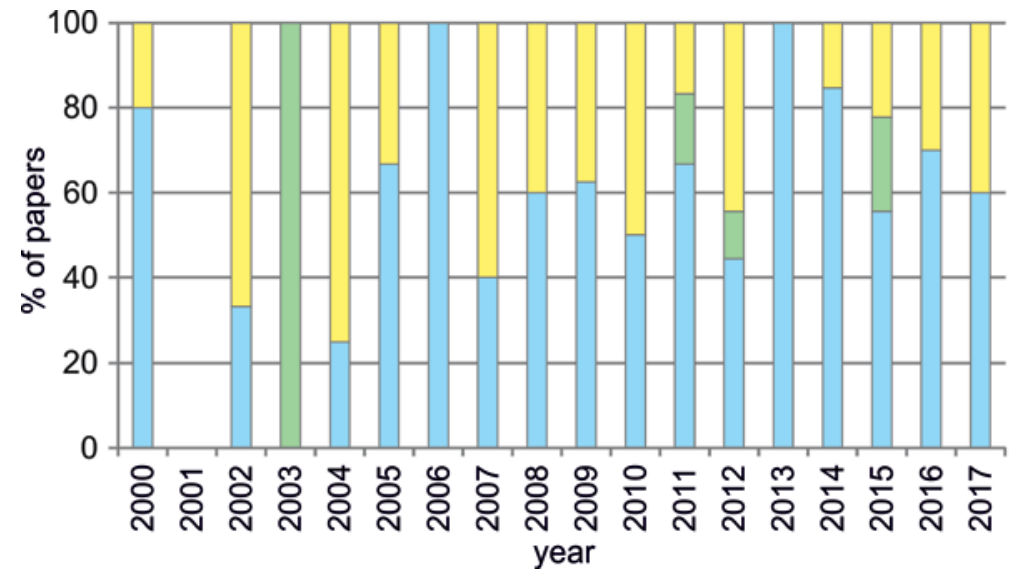

interactive

interactive \& non-interactive

non-interactive

Figure 5. Percentage of interactive and non-interactive maps Source: own elaboration

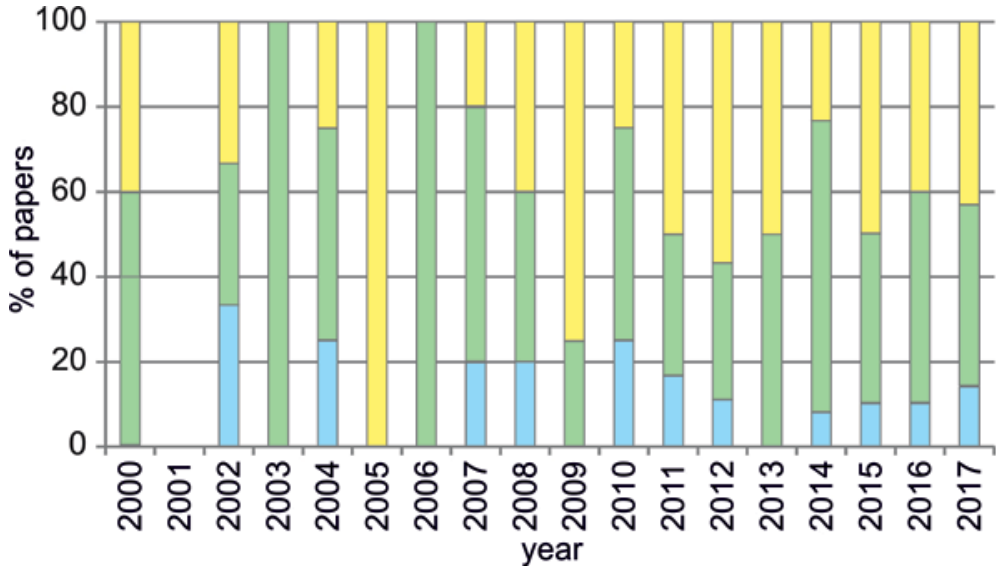

$\square$ qualitative

$\square$ qualitative \& quantitative

$\square$ quantitative

Figure 6. Percentage of maps elaborated with qualitative and quantitative methods of cartographic presentation Source: own elaboration

are distinguishable on the basis of nominal features (e.g. lake, river, pond). "Ordinal" is used when the features can be ranked (small, medium, big). "Quantitative" means that attributes are measurable (e.g. number of people, area, harvest in tonnes) (Robinson et al. 1995; Slocum 2010).

The character of the data has an impact on the choice of method of cartographic presentation. Qualitative data are used for: symbols (point, line, area) or chorochromatics. Quantitative and ordinal data are used for: diagrams, choropleths, isarithms, dots or quantitative signatures, which will subsequently be described as a group of quantitative methods.

Qualitative methods are much more often used in the analysed material (88\%) (Table 2.) They are most commonly used as city plans, tourist maps or maps for navigation. Little cartographic experience is needed to use them efficiently and effectively. They are quicker to understand when the required response time is measured.

The use of quantitative methods was more infrequent (57\%). They are used for depicting statistical data (Sun \& Li 2010). Participants with little expertise in cartography may find these map harder to interpret, and as a result longer response times may be needed.

In $43 \%$ of analysed cases both types of methods were used (Fig. 2). The most common example of this solution is a topographic map with contours (Ooms,et al. 2014; Murakoshi \& Higashi 2016; Ooms et al. 2016). Using it as a stimulus is coherent with ecological validity (Carter et al. 2008), as this type of map is commonly used, e.g. as the basis for tourist maps.

Familiarity with the presented area and data

Based on the analysed papers, maps were divided into three types, depicting data that was: fictional, familiar to the participant, or unfamiliar. Each type may refer to area and statistics. The base-map was not taken into consideration if questions did not refer to it. As in the case of, for example, a map depicting statistical data attributed to administrative units to a resident of the country in question (Harrower 2007; Opach \& Rød 2014).

It may seem that users' previous experience and knowledge is not an attribute of the stimulus, but of the study participants. Nonetheless, the stimuli must be carefully selected so as not to disrupt the findings, as the results may vary depending on participants' knowledge and experience.

This problem may be avoided by detailed selection of participants and establishment of a homogeneous group or preparation of a questionnaire and selection of data after the experiment. However, using a map of a distant or fictional territory as a stimulus may be less complicated than detailed verification of participants. 


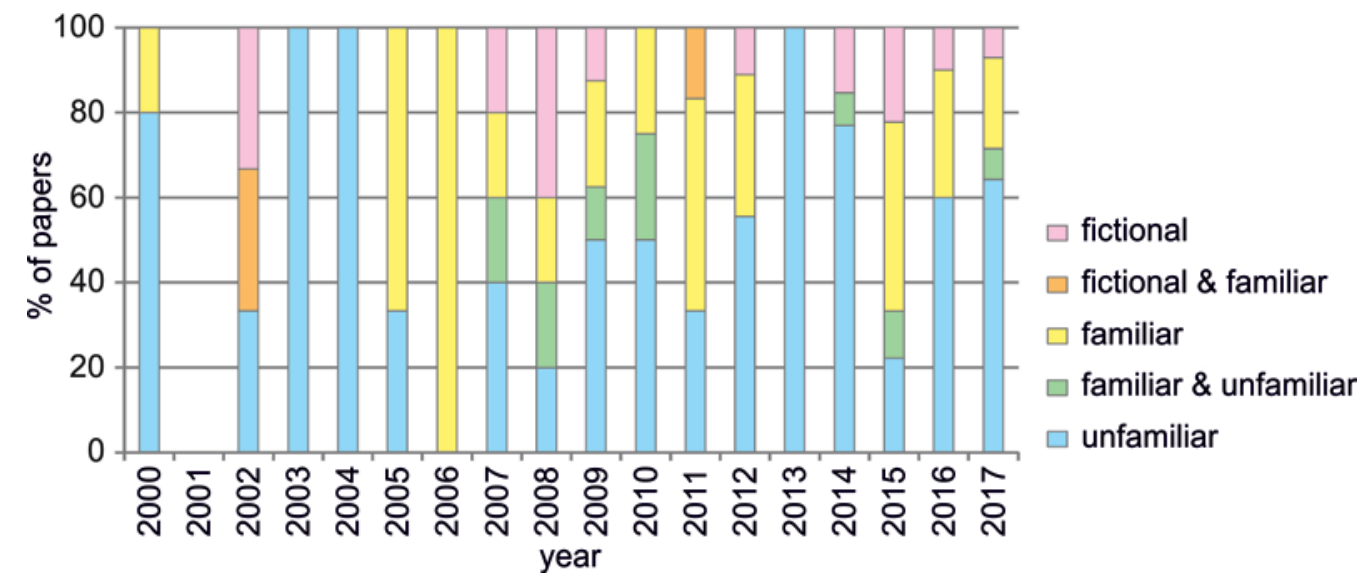

Figure 7. Percentage of maps of fictional, familiar and unfamiliar data or area Source: own elaboration

Table 2. Types of maps used in analysed papers

\begin{tabular}{|c|c|c|c|c|c|c|c|c|c|}
\hline Feature & \multicolumn{2}{|c|}{ Medium } & \multicolumn{2}{c|}{ Interactivity } & \multicolumn{2}{c|}{$\begin{array}{c}\text { Method of cartographic } \\
\text { presentation }\end{array}$} & \multicolumn{2}{c|}{$\begin{array}{c}\text { Familiarity with data or } \\
\text { area }\end{array}$} \\
\hline Type & paper & screen & $\begin{array}{c}\text { non- } \\
\text { interactive }\end{array}$ & interactive & qualitative & quantitative & fictional & familiar & unfamiliar \\
\hline $\begin{array}{c}\text { Number of } \\
\text { papers }\end{array}$ & 19 & 89 & 68 & 40 & 91 & 59 & 14 & 35 & 64 \\
\hline $\begin{array}{c}\text { Percent of } \\
\text { papers }\end{array}$ & $18,4 \%$ & $86,4 \%$ & $66,0 \%$ & $38,9 \%$ & $88,3 \%$ & $57,3 \%$ & $13,6 \%$ & $34,0 \%$ & $62,1 \%$ \\
\hline
\end{tabular}

Source: own elaboration

In over $60 \%$ of studies this most secure option was chosen and researchers decided to use a map of a distant region (Ooms et al. 2012) or statistical data (Fish et al. 2011) that was unlikely to be familiar to participants (Table 2). Use of a known area (34\%) may be hazardous, as participants rarely have comparable knowledge about the depicted territory. This issue is commonly present when large scale maps are used (e.g. plan of a city, topographic map). In some of the analysed instances only a portion of the participants was familiar with the data. This happened even in the case when the goal was not to compare effectiveness based on knowledge (Hochmair 2009) (Fig. 2).

The case of maps of fictional areas is very interesting. It can be stated that they should be included to "unknown". According to the definition of the International Cartographic Association, a map is a "symbolised representation of geographical reality" (A Strategic Plan for the ICA 2003-2011, p 17). By this definition, graphic representations of a fictional area cannot be called a "map", but recognised as a substitute. Three types of fictional maps may be enumerated: explicitly fictional (Lloyd \& Bunch 2005), maps pretending to present a real area (Fabrikant et al. 2008) or maps modified for the needs of a study (Gołębiowska 2015). There are several advantages and disadvantages of that solution. The main benefit is that participants do not know the depicted area. However, the objects on fictional maps often look artificial (e.g. trajectory of roads, borders or angular rivers).

\section{Study limitations}

The analysis was narrowed to papers published since 2000 in journals affiliated to the International Cartographic Association. A broader review would possibly show a wider scope of direction of experiments. What is more, if all types of geovisualisation were included the analysis would be extensive, as other types of aspects could be pointed out.

Unfortunately, the aspect of map complexity, which is a very important feature in empirical research, could not be assessed, as not all of the maps used in the analysed studies were included in the papers.

\section{Conclusions}

The elaboration of a consistent database of map types is a continuation of the work by Roth (2013a) and White (2017) and another step towards enhancing the reporting of empirical studies in cartography. Complying with this postulate would allow studies to be better validated and compared. In order to apply this proposal, explicit characteristic were defined. This allows this database to be further developed. Furthermore, the described database could be integrated with the database concerning participants by White (2017), which would allow profound insight to be gained into the empirical research conducted by cartographers since 2000 .

By juxtaposing maps according to objective criteria and performing a meta-analysis of the gathered data, the extensive group of studies can be more precisely characterised. The conclusions may serve other researchers who would like to make informed decisions when preparing their studies.

In the scope of every feature, one of the types could be observed to dominate (Table 2, Fig. 2). The most common types are maps displayed on a screen (88\%), non-interactive $(66 \%)$, qualitative $(88 \%)$ and unfamiliar $(62 \%)$. Maps that fall into all these dominant categories simultaneously were the subject of $25 \%$ of all experimental studies.

It is interesting that maps depicting qualitative data constituted $87 \%$ of interactive maps and $89 \%$ of non-interactive maps, $87 \%$ 
of screen maps and $94 \%$ of paper maps, so the prevalence of this feature is balanced. In the scope of the methods of cartographic presentation, two types (qualitative and quantitative) occurred simultaneously most frequently - in 47 cases (Fig. 2, Fig. 5). When it comes to map medium and reactiveness, both types were used in the same study five times (Fig. 2, Fig. 4). However, the disproportion between the use of paper and screen maps and between interactive and non-interactive maps is more significant (Fig. 2, Fig. 3).

In summary, meticulous description of experimental studies is crucial for proper construction of forthcoming research. Revisions of conducted experiments may constitute a frame for reporting study results.

\section{Acknowledgements}

I would like to thank the Reviewers for vital remarks, which helped me to improve my work.

Study conducted under the theme "Impact of advanced technologies on perception and abilities to use paper and electronic maps" (no 501-D119-86-0115500-15) was financed by a grant of the Ministry of Science and Higher Education.

Table 3. Types of maps

\begin{tabular}{|c|c|c|c|c|c|c|c|c|c|}
\hline Author(s) year & paper & screen & $\begin{array}{c}\text { non- } \\
\text { interactive }\end{array}$ & interactive & qualitative & quantitative & fictional & familiar & unfamiliar \\
\hline $\begin{array}{c}\text { Aerts, Clarke \& } \\
\text { Keuper } 2003\end{array}$ & & + & + & + & + & + & & & + \\
\hline $\begin{array}{c}\text { Aggett \& McColl } \\
2006\end{array}$ & & + & + & & + & + & & + & \\
\hline $\begin{array}{c}\text { Ahonen-Rainio \& } \\
\text { Kraak } 2005\end{array}$ & & + & + & & + & & & + & \\
\hline $\begin{array}{c}\text { Andrienko et al. } \\
2002\end{array}$ & & + & & + & & + & & & + \\
\hline Baker et al. 2016 & + & & + & & + & + & & & + \\
\hline $\begin{array}{c}\text { Bearman \& Lovett } \\
2010\end{array}$ & & + & & + & + & & & & + \\
\hline $\begin{array}{l}\text { Behrens, van } \\
\text { Elzakker \& } \\
\text { Schmidt } 2015\end{array}$ & + & + & + & + & + & & & + & \\
\hline $\begin{array}{l}\text { Bestgen et al. } \\
2017\end{array}$ & & + & + & & + & + & & & + \\
\hline $\begin{array}{c}\text { Biland \& Çöltekin } \\
2017\end{array}$ & & + & + & & & + & & & + \\
\hline $\begin{array}{c}\text { Bishop, Haggerty } \\
\text { \& Richardson } \\
2015 \\
\end{array}$ & & + & & + & + & + & & & + \\
\hline $\begin{array}{c}\text { Brügger, Fabrikant } \\
\text { \& Çöltekin } 2016\end{array}$ & & + & + & & + & + & & & + \\
\hline $\begin{array}{c}\text { Brychtova \& } \\
\text { Çöltekin } 2016\end{array}$ & & + & + & & + & & & & + \\
\hline $\begin{array}{c}\text { Brychtová \& } \\
\text { Çöltekin } 2017\end{array}$ & & + & + & & + & + & + & & \\
\hline $\begin{array}{c}\text { Bunch \& Lloyd } \\
2000 \\
\end{array}$ & & + & + & & + & & & + & \\
\hline $\begin{array}{l}\text { Cheung, Li \& } \\
\text { Chen } 2009 \\
\end{array}$ & & + & & + & + & & & + & \\
\hline $\begin{array}{c}\text { Czepkiewicz, } \\
\text { Jankowski \& } \\
\text { Młodkowski } 2017\end{array}$ & & + & & + & + & & & + & \\
\hline Deeb et al. 2014 & & + & + & & + & & + & & \\
\hline Deeb et al. 2015 & & + & + & & + & & + & & \\
\hline $\begin{array}{c}\text { Deeb, Ooms \& } \\
\text { Maeyer } 2012 \\
\end{array}$ & & + & + & & + & & + & & \\
\hline Demšar 2007 & & + & & + & + & + & & + & \\
\hline Dickmann 2012 & + & + & + & + & + & & & + & \\
\hline
\end{tabular}


MISCELLANEA GEOGRAPHICA - REGIONAL STUDIES ON DEVELOPMENT

Vol. 22 • No. 3 • 2018 • pp. 157-171 • ISSN: 2084-6118 • DOI: 10.2478/mgrsd-2018-0014

Continued Table 3. Types of maps

\begin{tabular}{|c|c|c|c|c|c|c|c|c|c|}
\hline Author(s) year & paper & screen & $\begin{array}{c}\text { non- } \\
\text { interactive }\end{array}$ & interactive & qualitative & quantitative & fictional & familiar & unfamiliar \\
\hline $\begin{array}{c}\text { Dickmann et al. } \\
2017\end{array}$ & & + & + & & + & & & & + \\
\hline Dillemuth 2005 & & + & + & & + & & & + & \\
\hline Dillemuth 2009 & + & + & + & & + & & + & & \\
\hline Dong et al. 2016 & & + & + & & + & & + & & \\
\hline $\begin{array}{c}\text { Dong, Ran \& } \\
\text { Wang } 2012 \\
\end{array}$ & & + & & + & & + & & & + \\
\hline Edler et al. 2014 & & + & + & & + & & + & & \\
\hline $\begin{array}{l}\text { Fabrikant et al. } \\
2008\end{array}$ & & + & + & & & + & + & & \\
\hline Field 2010 & + & & + & & + & + & & + & \\
\hline $\begin{array}{c}\text { Fish, Goldsberry \& } \\
\text { Battersby } 2011\end{array}$ & & + & + & & & + & & & + \\
\hline $\begin{array}{c}\text { Fujita \& Arikawa } \\
2011\end{array}$ & & + & & + & + & + & & + & \\
\hline Gołębiowska 2015 & & + & + & & + & + & + & & \\
\hline Griffin \& Bell 2009 & + & & + & & + & & & + & \\
\hline Harrower 2007 & & + & + & & & + & & & + \\
\hline $\begin{array}{c}\text { Harrower, } \\
\text { MacEachren \& } \\
\text { Griffin } 2000\end{array}$ & & + & & + & + & + & & & + \\
\hline $\begin{array}{l}\text { Hegarty et al. } \\
2009\end{array}$ & & + & + & & + & + & & & + \\
\hline Hennerdal 2017 & + & & + & & + & & & + & \\
\hline $\begin{array}{c}\text { Herbert \& Chen } \\
2015 \\
\end{array}$ & & + & + & + & + & & & + & \\
\hline Hochmair 2009 & & + & + & & + & & & + & + \\
\hline $\begin{array}{l}\text { Hope \& Hunter } \\
2007\end{array}$ & + & & + & & + & + & + & & \\
\hline $\begin{array}{c}\text { Huang, Schmidt \& } \\
\text { Gartner } 2012\end{array}$ & & + & & + & + & & & + & \\
\hline $\begin{array}{l}\text { Kiik, Nyström \& } \\
\text { Harrie } 2017\end{array}$ & & + & + & & + & & & & + \\
\hline $\begin{array}{c}\text { Kinkeldey et al. } \\
2014\end{array}$ & & + & + & & & + & & & + \\
\hline $\begin{array}{c}\text { Koletsis et al. } \\
2017\end{array}$ & + & + & & + & + & & & + & \\
\hline $\begin{array}{c}\text { Korpi, Hall \& } \\
\text { Ahonen-Rainio } \\
2014\end{array}$ & & + & + & & + & & & & + \\
\hline $\begin{array}{c}\text { Kubíček et al. } \\
2017 \\
\end{array}$ & & + & + & & + & + & & & + \\
\hline $\begin{array}{l}\text { Laakso \& Tiina } \\
\text { Sarjakoski } 2010\end{array}$ & & + & & + & + & + & & + & + \\
\hline Lai \& Yeh 2004 & & + & & + & + & + & & & + \\
\hline $\begin{array}{c}\text { Lautenschütz } \\
2012 \\
\end{array}$ & & + & & + & + & + & & & + \\
\hline $\begin{array}{c}\text { Leitner \& } \\
\text { Buttenfield } 2000\end{array}$ & & + & + & & + & + & & & + \\
\hline Li \& Ho 2004 & & + & & + & + & & & & + \\
\hline Liao et al. 2017 & & + & & + & + & & & & + \\
\hline
\end{tabular}


Continued Table 3. Types of maps

\begin{tabular}{|c|c|c|c|c|c|c|c|c|c|}
\hline Author(s) year & paper & screen & $\begin{array}{c}\text { non- } \\
\text { interactive }\end{array}$ & interactive & qualitative & quantitative & fictional & familiar & unfamiliar \\
\hline $\begin{array}{l}\text { Lloyd \& Bunch } \\
2005\end{array}$ & & + & & + & + & & & & + \\
\hline $\begin{array}{l}\text { Lloyd \& Bunch } \\
2008\end{array}$ & & + & + & & + & & + & & \\
\hline $\begin{array}{l}\text { Lloyd \& Patton } \\
2011\end{array}$ & & + & + & & + & & + & + & \\
\hline Lorenz et al. 2013 & + & & + & & + & & & & + \\
\hline $\begin{array}{c}\text { Luebbering \& } \\
\text { Carstensen } 2009\end{array}$ & & + & & + & + & & & & + \\
\hline $\begin{array}{c}\text { Luebbering et al. } \\
2008\end{array}$ & & + & & + & + & + & & & + \\
\hline Maggi et al. 2017 & & + & + & & + & + & & & + \\
\hline McKendry 2000 & & + & + & & + & + & & & + \\
\hline $\begin{array}{c}\text { Mendonça \& } \\
\text { Delazari } 2012\end{array}$ & & + & & + & + & & & + & \\
\hline $\begin{array}{l}\text { Mendonça \& } \\
\text { Delazari } 2014\end{array}$ & & + & + & & + & + & & & + \\
\hline $\begin{array}{c}\text { Michaelidou, } \\
\text { Nakos \& } \\
\text { Filippakopoulou } \\
2004\end{array}$ & + & & + & & + & + & & & + \\
\hline $\begin{array}{c}\text { Midtb } \varnothing \text { \& Nordvik } \\
2007\end{array}$ & & + & & + & + & & & & + \\
\hline $\begin{array}{c}\text { Muehlenhaus } \\
2012\end{array}$ & + & + & + & & + & + & & & + \\
\hline $\begin{array}{l}\text { Multimäki et al. } \\
2016\end{array}$ & & + & & + & & + & & & + \\
\hline $\begin{array}{l}\text { Murakoshi \& } \\
\text { Higashi } 2016\end{array}$ & + & & + & & + & + & & + & \\
\hline Nelson 2002 & & + & + & & + & + & + & + & \\
\hline $\begin{array}{c}\text { Nivala \& } \\
\text { Sarjakoski } 2007\end{array}$ & & + & & + & + & + & & + & + \\
\hline $\begin{array}{l}\text { Nivala, Brewster \& } \\
\text { Sarjakoski } 2008\end{array}$ & & + & & + & + & + & & + & + \\
\hline Nossum 2012 & & + & + & & + & + & & & + \\
\hline Nossum 2014 & & + & + & & + & + & & & + \\
\hline $\begin{array}{c}\text { Oksanen et al. } \\
2014\end{array}$ & + & & + & & + & + & & + & + \\
\hline Ooms et al. 2012 & & + & + & & + & & & & + \\
\hline Ooms et al. 2016 & + & & + & & + & + & & & + \\
\hline $\begin{array}{l}\text { Ooms, Dupont \& } \\
\text { Lapon } 2017\end{array}$ & & + & + & & + & + & & + & + \\
\hline $\begin{array}{c}\text { Ooms, Maeyer \& } \\
\text { Fack } 2014\end{array}$ & & + & + & & + & + & & & + \\
\hline $\begin{array}{c}\text { Opach \& Rød } \\
2014\end{array}$ & & + & & + & + & + & & & + \\
\hline Opach et al. 2017 & & + & & + & & + & & & + \\
\hline $\begin{array}{c}\text { Opach, } \\
\text { Gołębiowska \& } \\
\text { Fabrikant } 2014\end{array}$ & & + & & + & + & + & & & + \\
\hline Ory et al. 2015 & & + & + & & + & + & & + & + \\
\hline
\end{tabular}


MISCELLANEA GEOGRAPHICA - REGIONAL STUDIES ON DEVELOPMENT

Vol. 22 • No. 3 • 2018 • pp. 157-171 • ISSN: 2084-6118 • DOI: 10.2478/mgrsd-2018-0014

Table 3. Types of maps

\begin{tabular}{|c|c|c|c|c|c|c|c|c|c|}
\hline Author(s) year & paper & screen & $\begin{array}{c}\text { non- } \\
\text { interactive }\end{array}$ & interactive & qualitative & quantitative & fictional & familiar & unfamiliar \\
\hline $\begin{array}{l}\text { Paula Santil, } \\
\text { Sluter \& Meza } \\
\text { Bravo } 2011\end{array}$ & & + & + & & + & & & + & \\
\hline $\begin{array}{c}\text { Perdue \& Lobben } \\
2016\end{array}$ & + & & + & & + & & & & + \\
\hline Phipps 2011 & & + & + & + & + & + & & + & \\
\hline $\begin{array}{c}\text { Popelka \& } \\
\text { Brychtova } 2013\end{array}$ & & + & + & & + & + & & & + \\
\hline Poplin 2015 & & + & & + & + & & & + & \\
\hline $\begin{array}{l}\text { Poplin, Guan \& } \\
\text { Lewis } 2016\end{array}$ & & + & & + & + & + & & + & + \\
\hline $\begin{array}{l}\text { Pugliesi, Decanini } \\
\text { \& Tachibana } 2009\end{array}$ & & + & & + & + & & & & + \\
\hline Putto et al. 2014 & & + & + & & + & + & & & + \\
\hline $\begin{array}{c}\text { Raposo \& Brewer } \\
2014\end{array}$ & + & & + & & + & + & & & + \\
\hline Retchless 2014 & & + & + & & + & + & & & + \\
\hline $\begin{array}{c}\text { Reyes Nuñez \& } \\
\text { Juhász } 2015\end{array}$ & + & & + & & & + & & & + \\
\hline $\begin{array}{c}\text { Rigby \& Winter } \\
2016\end{array}$ & & + & & + & + & & & + & \\
\hline $\begin{array}{c}\text { Roth \& } \\
\text { MacEachren } 2016 \\
\end{array}$ & & + & & + & + & + & & + & \\
\hline Roth 2009 & & + & + & & + & + & & & + \\
\hline Sadahiro 2000 & + & & + & & + & & & & + \\
\hline $\begin{array}{c}\text { Saint-Marc et al. } \\
2017\end{array}$ & & + & & + & + & + & & & + \\
\hline Šavrič et al. 2015 & & + & + & & + & & & + & \\
\hline Slocum et al. 2004 & & + & & + & & + & & & + \\
\hline $\begin{array}{c}\text { Stigmar \& Harrie } \\
2011 \\
\end{array}$ & & + & + & & + & & & & + \\
\hline Sun \& Li 2010 & & + & + & & & + & & & + \\
\hline $\begin{array}{c}\text { Swienty et al. } \\
2008\end{array}$ & & + & + & & + & & & + & \\
\hline Wiegand 2002 & & + & & + & + & & + & & \\
\hline \multirow[t]{2}{*}{ TOTAL } & 19 & 89 & 68 & 40 & 91 & 59 & 14 & 35 & 64 \\
\hline & $18,4 \%$ & $86,4 \%$ & $66,0 \%$ & $38,8 \%$ & $88,3 \%$ & $57,3 \%$ & $13,6 \%$ & $34,0 \%$ & $62,1 \%$ \\
\hline
\end{tabular}

Source: own elaboration

\section{References}

A Strategic Plan for the ICA 2003-2011, A Strategic Plan for the International Cartographic Association 2003-2011, International Cartographic Association. Available from: $<$ http://icaci.org/files/documents/reference_docs/ICA_ Strategic_Plan_2003-2011.pdf>. [21 November 2017].

Andrienko, N, Andrienko, G, Voss, H, Bernardo, F, Hipolito, J \& Kretchmer, U 2002, 'Testing the Usability of Interactive Maps in CommonGIS', Cartography and Geographic Information Science, vol. 29, no. 4, pp. 325-342.

Axon, S, Speake, J \& Crawford, K 2012, 'At the next junction, turn left'. Attitudes towards Sat Nav use', Area, vol. 44, no. 2, pp. 170-177.
Behrens, J, van Elzakker, CPJM \& Schmidt, M 2015, 'Testing the Usability of OpenStreetMap's iD Tool', The Cartographic Journal, vol. 52, no. 2, pp. 177-184.

Carter, S, Mankoff, J, Klemmer, SR \& Matthews, T 2008, 'Exiting the Cleanroom. On Ecological Validity and Ubiquitous Computing', Human-Computer Interaction, vol. 23, no. 1, pp. 47-99.

Cartwright, W, Peterson, MP \& Gartner, G 2007, Multimedia Cartography, Springer-Verlag Berlin Heidelberg, Berlin, Heidelberg. Available from: <https://books.google.pl/books ?id=220SBgAAQBAJ\&printsec=frontcover\&hl=pl\#v=onepa ge\&q\&f=false>. Access date November 112017. 
Fabrikant, SI, Rebich-Hespanha, S, Andrienko, N, Andrienko, G \& Montello, DR 2008, 'Novel Method to Measure Inference Affordance in Static Small-Multiple Map Displays Representing Dynamic Processes', The Cartographic Journal, vol. 45, no. 3, pp. 201-215.

Fish, C, Goldsberry, KP \& Battersby, S 2011, 'Change Blindness in Animated Choropleth Maps. An Empirical Study', Cartography and Geographic Information Science, vol. 38, no. 4 , pp. 350-362.

Flannery, JJ 1956, The graduated circle; a description, analysis and evaluation of a quantitative map symbol. $\mathrm{PhD}$ thesis. Available from: $\quad<$ http://www.worldcat.org/title/graduated-circle-adescription-analysis-and-evaluation-of-a-quantitative-mapsymbol/oclc/607012888>. Access date November 112017.

Gilmartin, P 1992, 'Twenty-five Years of Cartographic Research. A Content Analysis', Cartography and Geographic Information Systems, vol. 19, no. 1, pp. 37-47.

Gołębiowska, I 2015, 'Legend Layouts for Thematic Maps. A Case Study Integrating Usability Metrics with the Thinking Aloud Method', The Cartographic Journal, vol. 52, no. 1, pp. 28-40.

Harrower, M 2007, 'Unclassed Animated Choropleth Maps', The Cartographic Journal, vol. 44, no. 4, pp. 313-320.

Harvey, F \& Kotting, J 2011, 'Teaching Mapping for Digital Natives. New Pedagogical Ideas for Undergraduate Cartography Education', Cartography and Geographic Information Science, vol. 38, no. 3, pp. 269-277.

Hochmair, H 2009, 'The Influence of Map Design on Route Choice from Public Transportation Maps in Urban Areas', The Cartographic Journal, vol. 46, no. 3, pp. 242-256.

Kraak, MJ \& Brown, A 2001, Web cartography. Developments and prospects, Taylor \& Francis, London, New York.

Kraak, M-J \& Ormeling, F 2015, Cartography. Visualization of spatial data, Routledge, London.

Lloyd, RE \& Bunch, RL 2005, 'Individual Differences in Map Reading Spatial Abilities Using Perceptual and Memory Processes', Cartography and Geographic Information Science, vol. 32, no. 1, pp. 33-46.

Montello, DR 2002, 'Cognitive Map-Design Research in the Twentieth Century: Theoretical and Empirical Approaches', Cartography and Geographic Information Science, vol. 29, no. 3, pp. 283-304.

Montello, DR 2009, 'Cognitive Research in GIScience. Recent Achievements and Future Prospects', Geography Compass, vol. 3, no. 5, pp. 1824-1840.

Montello, DR \& Freundschuh, S 2005, 'Cognition of Geographic Information' in A research agenda for geographic information science, eds McMaster R. B. \& Usery E. L., pp. 61-91.

Murakoshi, S \& Higashi, H 2016, 'Cognitive characteristics of navigational map use by mountaineers', International Journal of Cartography, vol. 1, no. 2, pp. 210-231.

Ooms, K, Maeyer, PD, Dupont, L, van der Veken, N, van de Weghe, N \& Verplaetse, S 2016, 'Education in cartography. What is the status of young people's map-reading skills?', Cartography and Geographic Information Science, vol. 43, no. 2, pp. 134-153.

Ooms, K, Maeyer, PD, Fack, V, van Assche, E \& Witlox, F 2012, 'Investigating the Effectiveness of an Efficient Label Placement Method Using Eye Movement Data', The Cartographic Journal, vol. 49, no. 3, pp. 234-246.

Ooms, K, Maeyer, P de \& Fack, V 2014, 'Study of the attentive behavior of novice and expert map users using eye tracking', Cartography and Geographic Information Science, vol. 41, no. 1 , pp. 37-54.

Opach, T, Gołębiowska, I \& Fabrikant, SI 2014, 'How Do People View Multi-Component Animated Maps?', The Cartographic Journal, vol. 51, no. 4, pp. 330-342.
Opach, T, Popelka, S, Dolezalova, J \& Rød, JK 2017, 'Star and polyline glyphs in a grid plot and on a map display. Which perform better?', Cartography and Geographic Information Science, vol. 17, no. 2, pp. 1-20.

Opach, T \& Rød, JK 2014, 'Do choropleth maps linked with parallel coordinates facilitate an understanding of multivariate spatial characteristics?', Cartography and Geographic Information Science, vol. 41, no. 5, pp. 413-429.

Oxford Dictionaries 2017. Available from: <https:// en.oxforddictionaries.com/>. [21 November 2017].

Petchenik, BB 1977, 'Cognition In Cartography', Cartographica: The International Journal for Geographic Information and Geovisualization, vol. 14, no. 1, pp. 117-128.

Prensky, M 2001, 'Digital Natives, Digital Immigrants Part 1', On the Horizon, vol. 9, no. 5, pp. 1-6.

Robinson, AH 1985, The look of maps. An examination of cartgraph. design, Univ. of Wisconsin Pr, Madison, Wis.

Robinson, AH, Morrison, JL, Muehrcke, PC, Kimerling, AJ \& Guptill, SC 1995, Elements of cartography. 6th ed, John Wiley \& Sons, New York, N.Y.

Roth, RE 2013a, 'Cartographic Interaction Primitives. Framework and Synthesis', The Cartographic Journal, vol. 49, no. 4, pp. 376-395.

Roth, RE 2013b, 'Interactive maps. What we know and what we need to know', Journal of Spatial Information Science, no. 6, pp. 59-115.

Roth, RE, Çöltekin, A, Delazari, L, Filho, HF, Griffin, A, Hall, A, Korpi, J, Lokka, I, Mendonça, A, Ooms, K \& van Elzakker, CPJM 2017, 'User studies in cartography. Opportunities for empirical research on interactive maps and visualizations', International Journal of Cartography, vol. 1, no. 1, pp. 1-29.

Saint-Marc, C, Villanova-Oliver, M, Davoine, P-A, Pams Capoccioni, C \& Chenier, D 2017, 'User testing of dynamic geovisualizations. Lessons learned and possible improvements for cartographic experiments', International Journal of Cartography, vol. 3, no. 1, pp. 88-101.

Slocum, T, Sluter, R, Kessler, F \& Yoder, S 2004, 'A Qualitative Evaluation of MapTime, A Program For Exploring Spatiotemporal Point Data', Cartographica: The International Journal for Geographic Information and Geovisualization, vol. 39, no. 3, pp. 43-68.

Slocum, TA 2010, Thematic cartography and geovisualization, Pearson Prentice Hall, Upper Saddle River, NJ.

Slocum, TA, Blok, C, Jiang Bin, Koussoulakou, A, Montello, DR, Fuhrmann, S \& Hedley, NR 2001, 'Cognitive and Usability Issues in Geovisualization', Cartography and Geographic Information Science, vol. 28, no. 1, pp. 61-75.

Speake, J 2016, '"l've got my Sat Nav, it's alright": Users' Attitudes towards, and Engagements with, Technologies of Navigation', The Cartographic Journal, vol. 52, no. 4, pp. 345-355.

Speake, J \& Axon, S 2013, '" Never Use 'Maps' Anymore": Engaging with Sat Nav Technologies and the Implications for Cartographic Literacy and Spatial Awareness', The Cartographic Journal, vol. 49, no. 4, pp. 326-336.

Sun, H \& Li, Z 2010, 'Effectiveness of Cartogram for the Representation of Spatial Data', The Cartographic Journal, vol. 47, no. 1, pp. 12-21.

Tanaka, M \& Ichikawa, T 1988, 'A visual user interface for map information retrieval based on semantic significance', IEEE Transactions on Software Engineering, vol. 14, no. 5, pp. 666-670.

Vosskühler, A, Nordmeier, V, Kuchinke, L \& Jacobs, AM 2008, 'OGAMA (Open Gaze and Mouse Analyzer). Open-source software designed to analyze eye and mouse movements in slideshow study designs', Behavior research methods, vol. 40, no. 4, pp. 1150-1162. 
White, T 2017, 'Identifying Best Practices by Examining Relationships Between Reporting in User Studies and Design of User Studies'. ICC 2017 Proceedings.

Żyszkowska, W 2015, 'Map perception. Theories and research in the second half of the twentieth century', Polish Cartographical Review, vol. 47, no. 4, pp. 179-190

\section{List of analysed papers}

Aerts, JCJH, Clarke, KC \& Keuper, AD 2003, 'Testing Popular Visualization Techniques for Representing Model Uncertainty', Cartography and Geographic Information Science, vol. 30, no. 3, pp. 249-261.

Aggett, G \& McColl, C 2006, 'Evaluating Decision Support Systems for PPGIS Applications', Cartography and Geographic Information Science, vol. 33, no. 1, pp. 77-92.

Ahonen-Rainio, P \& Kraak, M-J 2005, 'Deciding on Fitness for Use. Evaluating the Utility of Sample Maps as an Element of Geospatial Metadata', Cartography and Geographic Information Science, vol. 32, no. 2, pp. 101-112.

Andrienko, N, Andrienko, G, Voss, H, Bernardo, F, Hipolito, J \& Kretchmer, U 2002, 'Testing the Usability of Interactive Maps in CommonGIS', Cartography and Geographic Information Science, vol. 29, no. 4, pp. 325-342.

Baker, KM, Johnson, AC, Callahan, CN \& Petcovic, HL 2016, 'Use of cartographic images by expert and novice field geologists in planning fieldwork routes', Cartography and Geographic Information Science, vol. 43, no. 2, pp. 176-187.

Bearman, N \& Lovett, A 2010, 'Using Sound to Represent Positional Accuracy of Address Locations', The Cartographic Journal, vol. 47, no. 4, pp. 308-314.

Behrens, J, van Elzakker, CPJM \& Schmidt, M 2015, 'Testing the Usability of OpenStreetMap's iD Tool', The Cartographic Journal, vol. 52, no. 2, pp. 177-184.

Bestgen, A-K, Edler, D, Müller, C, Schulze, P, Dickmann, F \& Kuchinke, L 2017, 'Where Is It (in the Map)? Recall and Recognition of Spatial Information', Cartographica: The International Journal for Geographic Information and Geovisualization, vol. 52, no. 1, pp. 80-97.

Biland, J \& Çöltekin, A 2017, 'An empirical assessment of the impact of the light direction on the relief inversion effect in shaded relief maps. NNW is better than NW', Cartography and Geographic Information Science, vol. 44, no. 4, pp. 358-372.

Bishop, BW, Haggerty, KC \& Richardson, BE 2015, 'Usability of E-government mapping applications. Lessons learned from the US National Atlas', International Journal of Cartography, vol. 1, no. 2, pp. 134-150.

Brügger, A, Fabrikant, SI \& Çöltekin, A 2016, 'An empirical evaluation of three elevation change symbolization methods along routes in bicycle maps', Cartography and Geographic Information Science, vol. 44, no. 5, pp. 436-451.

Brychtova, A \& Coltekin, A 2016, 'An Empirical User Study for Measuring the Influence of Colour Distance and Font Size in Map Reading Using Eye Tracking', The Cartographic Journal, vol. 53, no. 3, pp. 202-212.

Brychtová, A \& Çöltekin, A 2017, 'The effect of spatial distance on the discriminability of colors in maps', Cartography and Geographic Information Science, vol. 44, no. 3, pp. 229-245.

Bunch, R \& Lloyd, R 2000, 'The Search for Boundaries on Maps. Color Processing and Map Pattern Effects', Cartography and Geographic Information Science, vol. 27, no. 1, pp. 15-30.

Cheung, YK, Li, Z \& Chen, W 2009, 'Integration of Cognitionbased Content Zooming and Progressive Visualization for
Mobile-based Navigation', The Cartographic Journal, vol 46, no. 3, pp. 268-272.

Czepkiewicz, M, Jankowski, P \& Młodkowski, M 2017, ‘Geoquestionnaires in urban planning. Recruitment methods, participant engagement, and data quality', Cartography and Geographic Information Science, vol. 44, no. 6, pp. 551-567.

Deeb, R, Ooms, K \& Maeyer, P de 2012, 'Typography in the Eyes of Bertin, Gender and Expertise Variation', The Cartographic Journal, vol. 49, no. 2, pp. 176-185.

Deeb, R, Ooms, K, van Eetvelde, V \& Maeyer, P de 2015, 'Towards a Deeper Understanding of Cartographic Text Visualisation. Assessment of User Preferences and Colour Influence', The Cartographic Journal, vol. 52, no. 4, pp. 325-335.

Deeb, R, Ooms, K, Vanopbroeke, V \& Maeyer, P de 2014, 'Evaluating the Efficiency of Typographic Design. Gender and Expertise Variation', The Cartographic Journal, vol. 51, no. 1 , pp. $75-86$.

Demšar, U 2007, 'Combining Formal and Exploratory Methods for Evaluation of an Exploratory Geovisualization Application in a Low-Cost Usability Experiment', Cartography and Geographic Information Science, vol. 34, no. 1, pp. 29-45.

Dickmann, F 2012, 'City Maps Versus Map-Based Navigation Systems - An Empirical Approach to Building Mental Representations', The Cartographic Journal, vol. 49, no. 1, pp. 62-69.

Dickmann, F, Edler, D, Bestgen, A-K \& Kuchinke, L 2017, 'Exploiting Illusory Grid Lines for Object-Location Memory Performance in Urban Topographic Maps', The Cartographic Journal, vol. 54, no. 3, pp. 242-253.

Dillemuth, J 2005, 'Map Design Evaluation for Mobile Display', Cartography and Geographic Information Science, vol. 32, no. 4 , pp. 285-301.

Dillemuth, JA 2009, 'Navigation Tasks with Small-Display Maps. The Sum of the Parts Does Not Equal the Whole', Cartographica: The International Journal for Geographic Information and Geovisualization, vol. 44, no. 3, pp. 187-200.

Dong, W, Ran, J \& Wang, J 2012, 'Effectiveness and Efficiency of Map Symbols for Dynamic Geographic Information Visualization', Cartography and Geographic Information Science, vol. 39, no. 2, pp. 98-106.

Dong, W, Zhang, S, Liao, H, Liu, Z, Li, Z \& Yang, X 2016, 'Assessing the Effectiveness and Efficiency of Map Colour for Colour Impairments Using an Eye-tracking Approach', The Cartographic Journal, vol. 53, no. 2, pp. 166-176.

Edler, D, Huber, O, Knust, C, Buchroithner, MF \& Dickmann, F 2014, 'Spreading Map Information over Different Depth Layers - An Improvement for Map-Reading Efficiency?', Cartographica: The International Journal for Geographic Information and Geovisualization, vol. 49, no. 3, pp. 153163.

Fabrikant, SI, Rebich-Hespanha, S, Andrienko, N, Andrienko, G \& Montello, DR 2008, 'Novel Method to Measure Inference Affordance in Static Small-Multiple Map Displays Representing Dynamic Processes', The Cartographic Journal, vol. 45, no. 3, pp. 201-215. 
Field, K 2010, 'Gravity is Your Friend but Every Turn is a Leap of Faith. Design and Testing a Schematic Map for Ski Resort Trails', The Cartographic Journal, vol. 47, no. 3, pp. 222-237.

Fish, C, Goldsberry, KP \& Battersby, S 2011, 'Change Blindness in Animated Choropleth Maps. An Empirical Study', Cartography and Geographic Information Science, vol. 38, no. 4, pp. 350-362.

Fujita, H \& Arikawa, M 2011, 'A User Study of a Map-Based Slideshow Editor', Cartographica: The International Journal for Geographic Information and Geovisualization, vol. 46, no. 2, pp. 74-82

Gołębiowska, I 2015, 'Legend Layouts for Thematic Maps. A Case Study Integrating Usability Metrics with the Thinking Aloud Method', The Cartographic Journal, vol. 52, no. 1, pp. 28-40.

Griffin, AL \& Bell, S 2009, 'Applications of Signal Detection Theory to Geographic Information Science', Cartographica: The International Journal for Geographic Information and Geovisualization, vol. 44, no. 3, pp. 145-158.

Harrower, M 2007, 'Unclassed Animated Choropleth Maps', The Cartographic Journal, vol. 44, no. 4, pp. 313-320.

Harrower, M, MacEachren, A \& Griffin, AL 2000, 'Developing a Geographic Visualization Tool to Support Earth Science Learning', Cartography and Geographic Information Science, vol. 27, no. 4, pp. 279-293.

Hegarty, M, Smallman, HS, Stull, AT \& Canham, MS 2009, 'Naïve Cartography. How Intuitions about Display Configuration Can Hurt Performance', Cartographica: The International Journal for Geographic Information and Geovisualization, vol. 44 , no. 3 , pp. 171-186.

Hennerdal, P 2017, 'Continuity markers as an aid for children in finding the peripheral continuity of world maps', Cartography and Geographic Information Science, vol. 44, no. 1, pp. 76-85.

Herbert, G \& Chen, X 2015, 'A comparison of usefulness of 2D and $3 D$ representations of urban planning', Cartography and Geographic Information Science, vol. 42, no. 1, pp. 22-32.

Hochmair, H 2009, 'The Influence of Map Design on Route Choice from Public Transportation Maps in Urban Areas', The Cartographic Journal, vol. 46, no. 3, pp. 242-256.

Hope, S \& Hunter, GJ 2007, 'Testing the Effects of Thematic Uncertainty on Spatial Decision-making', Cartography and Geographic Information Science, vol. 34, no. 3, pp. 199-214.

Huang, H, Schmidt, M \& Gartner, G 2012, 'Spatial Knowledge Acquisition with Mobile Maps, Augmented Reality and Voice in the Context of GPS-based Pedestrian Navigation. Results from a Field Test', Cartography and Geographic Information Science, vol. 39, no. 2, pp. 107-116.

Kiik, A, Nyström, M \& Harrie, L 2017, 'Cartographic Design Matters - A Comparison of Thematic Polygon Design', The Cartographic Journal, vol. 54, no. 1, pp. 24-35.

Kinkeldey, C, Mason, J, Klippel, A \& Schiewe, J 2014, 'Evaluation of noise annotation lines. Using noise to represent thematic uncertainty in maps', Cartography and Geographic Information Science, vol. 41, no. 5, pp. 430-439.

Koletsis, E, van Elzakker, CPJM, Kraak, M-J, Cartwright, W, Arrowsmith, C \& Field, K 2017, 'An investigation into challenges experienced when route planning, navigating and wayfinding', International Journal of Cartography, vol. 3, no. 1, pp. 4-18.

Korpi, J, Hall, A \& Ahonen-Rainio, P 2014, 'An experimental analysis of three methods for highlighting colorful pictographic symbols', Cartography and Geographic Information Science, vol. 41, no. 1, pp. 27-36.

Kubíček, P, Šašinka, Č, Stachoň, Z, Štěrba, Z, Apeltauer, J \& Urbánek, T 2017, 'Cartographic Design and Usability of
Visual Variables for Linear Features', The Cartographic Journal, vol. 54, no. 1, pp. 91-102.

Laakso, M \& Tiina Sarjakoski, L 2010, 'Sonic Maps for HikingUse of Sound in Enhancing the Map Use Experience', The Cartographic Journal, vol. 47, no. 4, pp. 300-307.

Lai, P-C \& Yeh, AG-O 2004, 'Assessing the Effectiveness of Dynamic Symbols in Cartographic Communication', The Cartographic Journal, vol. 41, no. 3, pp. 229-244.

Lautenschütz, A-K 2012, 'Map Readers' Assessment of Path Elements and Context to Identify Movement Behaviour in Visualisations', The Cartographic Journal, vol. 49, no. 4, pp. 337-349.

Leitner, M \& Buttenfield, BP 2000, 'Guidelines for the Display of Attribute Certainty', Cartography and Geographic Information Science, vol. 27, no. 1, pp. 3-14.

Li, Z \& Ho, A 2004, 'Design of Multi-Scale and Dynamic Maps for Land Vehicle Navigation', The Cartographic Journal, vol. 41, no. 3, pp. 265-270.

Liao, H, Dong, W, Peng, C \& Liu, H 2017, 'Exploring differences of visual attention in pedestrian navigation when using $2 \mathrm{D}$ maps and 3D geo-browsers', Cartography and Geographic Information Science, vol. 44, no. 6, pp. 474-490.

Lloyd, RE \& Bunch, RL 2005, 'Individual Differences in Map Reading Spatial Abilities Using Perceptual and Memory Processes', Cartography and Geographic Information Science, vol. 32, no. 1, pp. 33-46.

Lloyd, RE \& Bunch, RL 2008, 'Explaining Map-reading Performance Efficiency. Gender, Memory, and Geographic Information', Cartography and Geographic Information Science, vol. 35, no. 3, pp. 171-202.

Lloyd, RE \& Patton, D 2011, 'Maps and Biased Familiarity. Cognitive Distance Error and Reference Points', Cartographica: The International Journal for Geographic Information and Geovisualization, vol. 46, no. 3, pp. 170184.

Lorenz, A, Thierbach, C, Baur, N \& Kolbe, TH 2013, 'Map design aspects, route complexity, or social background? Factors influencing user satisfaction with indoor navigation maps', Cartography and Geographic Information Science, vol. 40, no. 3, pp. 201-209.

Luebbering, CR \& Carstensen, LW 2009, 'Varying Display Size and Resolution for Digitizing Vector and Raster Targets. A Study of Digitizing Performance on Multiple-Monitor HighResolution Displays', Cartographica: The International Journal for Geographic Information and Geovisualization, vol. 44, no. 4, pp. 256-273.

Luebbering, CR, Carstensen, LW, Campbell, JB \& Grossman, LS 2008, 'Expanding Display Size and Resolution for Viewing Geospatial Data. A User Study with Multiple-Monitor High-Resolution Displays', Cartography and Geographic Information Science, vol. 35, no. 3, pp. 203-219.

Maggi, S, Fabrikant, SI, Imbert, J-P \& Hurter, C 2017, 'How Do Display Design and User Characteristics Matter in Animations? An Empirical Study with Air Traffic Control Displays 1', Cartographica: The International Journal for Geographic Information and Geovisualization, vol. 52, no. 4, pp. 1-13.

McKendry, J 2000, 'The Influence of Map Design on Resource Management Decision Making', Cartographica: The International Journal for Geographic Information and Geovisualization, vol. 37, no. 2, pp. 13-27.

Mendonça, A \& Delazari, L 2014, 'Testing Subjective Preference and Map Use Performance. Use of Web Maps for Decision Making in the Public Health Sector', Cartographica: The International Journal for Geographic Information and Geovisualization, vol. 49, no. 2, pp. 114-126. 
Mendonça, ALA de \& Delazari, LS 2012, 'Remote Evaluation of the Execution of Spatial Analysis Tasks with Interactive Web Maps. A Functional and Quantitative Approach', The Cartographic Journal, vol. 49, no. 1, pp. 7-20.

Michaelidou, E, Nakos, B \& Filippakopoulou, V 2004, 'The Ability of Elementary School Children to Analyse General Reference and Thematic Maps', Cartographica: The International Journal for Geographic Information and Geovisualization, vol. 39 , no. 4 , pp. $65-88$.

Midtbø, T \& Nordvik, T 2007, 'Effects of Animations in Zooming and Panning Operations on Web maps. A Web-based Experiment', The Cartographic Journal, vol. 44, no. 4, pp. 292-303.

Muehlenhaus, I 2012, 'If Looks Could Kill. The Impact of Different Rhetorical Styles on Persuasive Geocommunication', The Cartographic Journal, vol. 49, no. 4, pp. 361-375.

Multimäki, S, Mäkilä, A, Korpi, J \& Ahonen-Rainio, P 2016, 'Experiencing bivariate colour scales on animated maps', International Journal of Cartography, vol. 2, no. 1, pp. 20-37.

Murakoshi, S \& Higashi, H 2016, 'Cognitive characteristics of navigational map use by mountaineers', International Journal of Cartography, vol. 1, no. 2, pp. 210-231.

Nelson, E 2002, 'The Impact of Bivariate Symbol Design on Task Performance in a Map Setting', Cartographica: The International Journal for Geographic Information and Geovisualization, vol. 37, no. 4, pp. 61-78.

Nivala, A-M, Brewster, S \& Sarjakoski, TL 2008, 'Usability Evaluation of Web Mapping Sites', The Cartographic Journal, vol. 45, no. 2, pp. 129-138.

Nivala, A-M \& Sarjakoski, TL 2007, 'User Aspects of Adaptive Visualization for Mobile Maps', Cartography and Geographic Information Science, vol. 34, no. 4, pp. 275-284.

Nossum, AS 2012, 'Semistatic Animation - Integrating Past, Present and Future in Map Animations', The Cartographic Journal, vol. 49, no. 1, pp. 43-54.

Nossum, AS 2014, 'Exploring Eye Movement Patterns on Cartographic Animations Using Projections of a SpaceTime-Cube', The Cartographic Journal, vol. 51, no. 3, pp. 249-256.

Oksanen, J, Halkosaari, H-M, Sarjakoski, T \& Sarjakoski, LT 2014, 'A User Study of Experimental Maps for Outdoor Activities', Cartographica: The International Journal for Geographic Information and Geovisualization, vol. 49, no. 3, pp. 188-201.

Ooms, K, Dupont, L \& Lapon, L 2017, 'Mixing Methods and Triangulating Results to Study the Influence of Panning on Map Users' Attentive Behaviour', The Cartographic Journal, vol. 54, no. 3, pp. 196-213.

Ooms, K, Maeyer, P de, Dupont, L, van der Veken, N, van de Weghe, N \& Verplaetse, S 2015, 'Education in cartography. What is the status of young people?s map-reading skills?', Cartography and Geographic Information Science, vol. 43, no. 2, pp. 134-153.

Ooms, K, Maeyer, P de \& Fack, V 2014, 'Study of the attentive behavior of novice and expert map users using eye tracking', Cartography and Geographic Information Science, vol. 41, no. 1 , pp. 37-54.

Ooms, K, Maeyer, P de, Fack, V, van Assche, E \& Witlox, F 2012, 'Investigating the Effectiveness of an Efficient Label Placement Method Using Eye Movement Data', The Cartographic Journal, vol. 49, no. 3, pp. 234-246.

Opach, T, Gołębiowska, I \& Fabrikant, SI 2014, 'How Do People View Multi-Component Animated Maps?', The Cartographic Journal, vol. 51, no. 4, pp. 330-342.

Opach, T, Popelka, S, Dolezalova, J \& Rød, JK 2017, 'Star and polyline glyphs in a grid plot and on a map display. Which perform better?', Cartography and Geographic Information Science, vol. 17, no. 2, pp. 1-20.

Opach, T \& Rød, JK 2014, 'Do choropleth maps linked with parallel coordinates facilitate an understanding of multivariate spatial characteristics?', Cartography and Geographic Information Science, vol. 41, no. 5, pp. 413-429.

Ory, J, Christophe, S, Fabrikant, SI \& Bucher, B 2015, 'How Do Map Readers Recognize a Topographic Mapping Style?', The Cartographic Journal, vol. 52, no. 2, pp. 193-203.

Paula Santil, FL de, Sluter, CR \& Meza Bravo, JV 2011, 'Mental Categorisation and Classification Process of Information in Maps', The Cartographic Journal, vol. 48, no. 2, pp. 146152.

Perdue, NA \& Lobben, AK 2016, 'Understanding Spatial Pattern Cognition from Tactile Maps and Graphics', Cartographica: The International Journal for Geographic Information and Geovisualization, vol. 51, no. 2, pp. 103-110.

Phipps, A 2011, 'Comparisons of Residents' Perceptions of Patterns and Trends on Computer-Animated Maps and Graphs and on Google Maps of Events in Their Neighbourhoods', Cartographica: The International Journal for Geographic Information and Geovisualization, vol. 46, no. 3, pp. 185-199.

Popelka, S \& Brychtova, A 2013, 'Eye-tracking Study on Different Perception of 2D and 3D Terrain Visualisation', The Cartographic Journal, vol. 50, no. 3, pp. 240-246.

Poplin, A 2015, 'How user-friendly are online interactive maps? Survey based on experiments with heterogeneous users', Cartography and Geographic Information Science, vol. 42, no. 4 , pp. 358-376.

Poplin, A, Guan, W \& Lewis, B 2016, 'Online Survey of Heterogeneous Users and Their Usage of the Interactive Mapping Platform WorldMap', The Cartographic Journal, pp. 1-19.

Pugliesi, EA, Decanini, MMS \& Tachibana, VM 2009, 'Evaluation of the Cartographic Communication Performance of a Route Guidance and Navigation System', Cartography and Geographic Information Science, vol. 36, no. 2, pp. 193-207.

Putto, K, Kettunen, P, Torniainen, J, Krause, CM \& Tiina Sarjakoski, L 2014, 'Effects of Cartographic Elevation Visualizations and Map-reading Tasks on Eye Movements', The Cartographic Journal, vol. 51, no. 3, pp. 225-236.

Raposo, P \& Brewer, CA 2014, 'Landscape Preference and Map Readability in Design Evaluation of Topographic Maps with an Orthoimage Background', The Cartographic Journal, vol. 51 , no. 1 , pp. 25-37.

Retchless, DP 2014, 'Communicating climate change. Spatial analog versus color-banded isoline maps with and without accompanying text', Cartography and Geographic Information Science, vol. 41, no. 1, pp. 55-74.

Reyes Nuñez, JJ \& Juhász, B 2015, 'Hungarian survey on the use of cartograms in school cartography', International Journal of Cartography, vol. 1, no. 1, pp. 5-17.

Rigby, M \& Winter, S 2016, 'Usability of an opportunistic interface concept for ad hoc ride-sharing', International Journal of Cartography, vol. 2, no. 2, pp. 115-147.

Roth, RE 2009, 'The Impact of User Expertise on Geographic Risk Assessment under Uncertain Conditions', Cartography and Geographic Information Science, vol. 36, no. 1, pp. 29-43.

Roth, RE \& MacEachren, AM 2016, 'Geovisual analytics and the science of interaction. An empirical interaction study', Cartography and Geographic Information Science, vol. 43, no. 1 , pp. $30-54$.

Sadahiro, Y 2000, 'Perception of Spatial Dispersion in Point Distributions', Cartography and Geographic Information Science, vol. 27 , no. 1, pp. 51-64. 
Saint-Marc, C, Villanova-Oliver, M, Davoine, P-A, Pams Capoccioni, C \& Chenier, D 2017, 'User testing of dynamic geovisualizations. Lessons learned and possible improvements for cartographic experiments', International Journal of Cartography, vol. 3, no. 1, pp. 88-101.

Šavrič, B, Jenny, B, White, D \& Strebe, DR 2015, 'User preferences for world map projections', Cartography and Geographic Information Science, vol. 42, no. 5, pp. 398-409.

Slocum, T, Sluter, R, Kessler, F \& Yoder, S 2004, 'A Qualitative Evaluation of MapTime, A Program For Exploring Spatiotemporal Point Data', Cartographica: The International Journal for Geographic Information and Geovisualization, vol. 39, no. 3, pp. 43-68.

Stigmar, H \& Harrie, L 2011, 'Evaluation of Analytical Measures of Map Legibility', The Cartographic Journal, vol. 48, no. 1, pp. 41-53.

Sun, H \& Li, Z 2010, 'Effectiveness of Cartogram for the Representation of Spatial Data', The Cartographic Journal, vol. 47, no. 1, pp. 12-21.

Swienty, O, Reichenbacher, T, Reppermund, S \& Zihl, J 2008, 'The Role of Relevance and Cognition in Attention-guiding Geovisualisation', The Cartographic Journal, vol. 45, no. 3, pp. 227-238.

Wiegand, P 2002, 'School Students' Mental Representations of Thematic Point Symbol Maps', The Cartographic Journal, vol. 39, no. 2, pp. 125-136. 